\title{
Global Neurodiverse Support
}

\section{Systems}

\section{Primary Research Findings on Key Challenges and Optimized Solutions in Mumbai, India}

\begin{abstract}
Neurodiversity refers to the inherent differences in the structure and functioning of the brain causing neurological variations. These include but are not limited to Autism, ADHD, Learning disabilities, Tourette's syndrome. However, the understanding of these conditions and the support available has considerable scope for improvement, and new advances are continually being made. This leads to a vast disparity in the support systems available for the neurodiverse community across different countries. This paper comprises of two parts; the first half includes an analysis of the global support systems for neurodiverse conditions based on the current research available for different regions; the second half includes a primary research study conducted supported by gap-identification analysis of Mumbai's (India) neurodiverse support system. A set of suggestions is formulated based on observations such as the lack of a multidisciplinary approach, poor levels of coordination, low levels of inclusion in the education sector from the research survey, to improve the support provided to the neurodiverse community. Based on these evidence-based solutions further research can be conducted to mitigate the problems faced by the neurodiverse community and its coexisting support systems.
\end{abstract}

Ritwika Roy, Shreya Jain

ReservoirNow.com

Ritwika@reservoirnow.com

Cite as; Roy, R. \& Jain, S. (2021) Global neurodiversity support systems Primary research findings on key challenges and optimised solutions in Mumbai, India. The Physician vol 6; Issue 3: 1-22 ePub 27.12.2020 DOI: https://doi.org/10.38192/1.6.3.9

\section{Article Information}

Submitted 15.12.2020

Published 28.12.2020

Open Access - Creative Commons Licence International Derivative v4.0

Keywords: Neurodiverse, Autism, Cerebral Palsy, Downs syndrome, Support system, Healthcare

\section{Introduction}

\section{Neurodiversity}

The term "Neurodiversity" was coined by the Australian sociologist, Judy Singer in the late 1990s $(1,2)$. Singer, who was on the autism spectrum herself refrained from agreeing to the idea that people with autism were disabled (1). Instead, she believed that their brain just functioned differently from others $(1,2)$. Thus, the term neurodiversity was quickly picked up by activists, the medical community, and advocates and is now being actively used to promote inclusion in the corporate and education sphere (1). 
Just as the term goes, neurodiversity refers to the differences in brain structure and function $(3,4)$. These differences stem from how the brain is "wired", thus affecting its functioning. It indicates that brain differences are only differences, nothing more nor less $(2,3)$. These could be structural, functional, or both, thus impacting an individual's behaviour $(1,2,4)$. Coined as an umbrella term, "neurodiversity" encompasses a variety of disorders and conditions as demonstrated in Fig.1.0 (5). Thus, conditions such as Autism, Attention Deficit Hyperactivity Disorder (ADHD), Tourette's syndrome, learning disabilities are not abnormal, they are just diverse expressions of the differences in the neurological structures and functioning of the brain $(1,4)$. Alongside this, this paper also took into consideration, conditions/disorders like Cerebral Palsy and Down's syndrome which do not fall into the rigorous spectrum of "Neurodiversity" but have neurological implications.

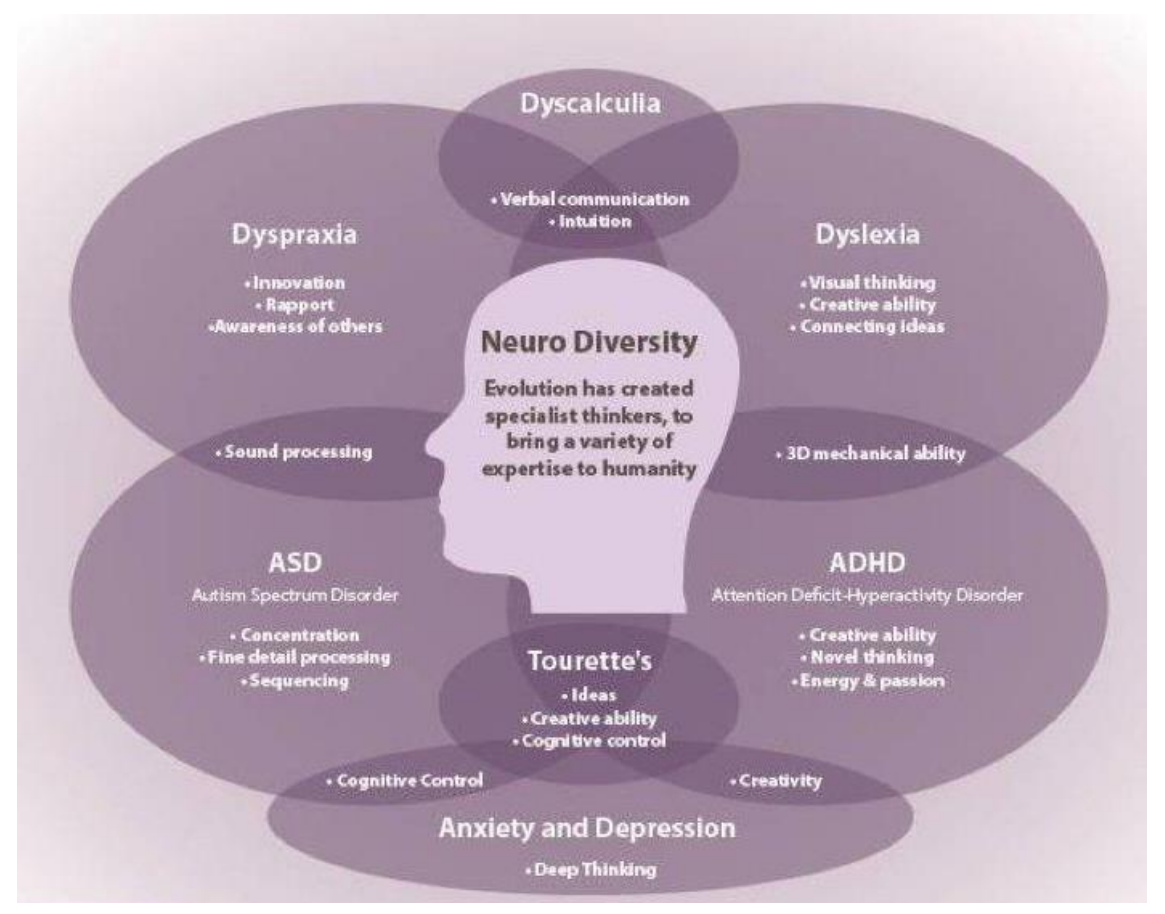

Figure 1.0 Representation of Neurodiversity and its associated conditions (5)

\section{Neurodiverse conditions/syndromes considered for the study}

We conducted an extensive literature review focusing on three conditions/disorders, along with a study of the existing support systems in place across the globe: ${ }^{1}$

- Autism spectrum disorder (ASD): an umbrella term for a set of complex neurodevelopmental disorders that include autism, childhood disintegrative disorders, and Asperger's syndrome $(6,7,8)$. Impairments in early brain development affect all aspects of a child's functioning $(6,7)$. This impairment affects the abilities to interact, communicate and adjust to new surroundings and social settings $(6,8)$

- Cerebral Palsy (CP): an umbrella term for a group of neurological disorders that appear in infancy or early childhood permanently affecting muscle coordination, balance, and body movement $(9,10)$. The region of the cerebral cortex that controls muscle movement and coordination is affected, which causes this impairment (9).

- Down's syndrome (DS): a genetic disorder caused when a child is born with an extra copy of the $21^{\text {st }}$ chromosome, thus the name trisomy $21(11,12)$. This syndrome is accompanied by mental and physical developmental delays and disabilities $(12,13)$. This extra chromosome serves as a hindrance when the brain and other physical features start to develop $(11,13)$.

\section{Existing Support System}

Most of the neurological conditions/conditions having neurological implications do not have a specific medical test, medicine, or treatment that can completely cure them (14). After the diagnosis of the particular disorder/condition,

\footnotetext{
${ }^{1}$ The conditions/disorders considered for this study are not strictly restricted within the boundaries of the umbrella term: Neurodiversity. DS and CP have neurological complications and are thus considered as a part of the neurodiverse spectrum for this study
} 
a team of service providers work together holistically and collaborate with the child and the parents to come up with a unique recommendation plan $(13,15,16,17)$. Using a multi-disciplinary treatment approach, involving doctors, therapists, counsellors, special educators, and parent-mediated interventions, an individual treatment plan is created $(6,8,14,18,19)$. A personalized treatment strategy comprising of a unique recommendation plan accommodating the child's needs and wants along with parental goals is usually implemented for the treatment and rehabilitation journey $(13,15,16,17)$.

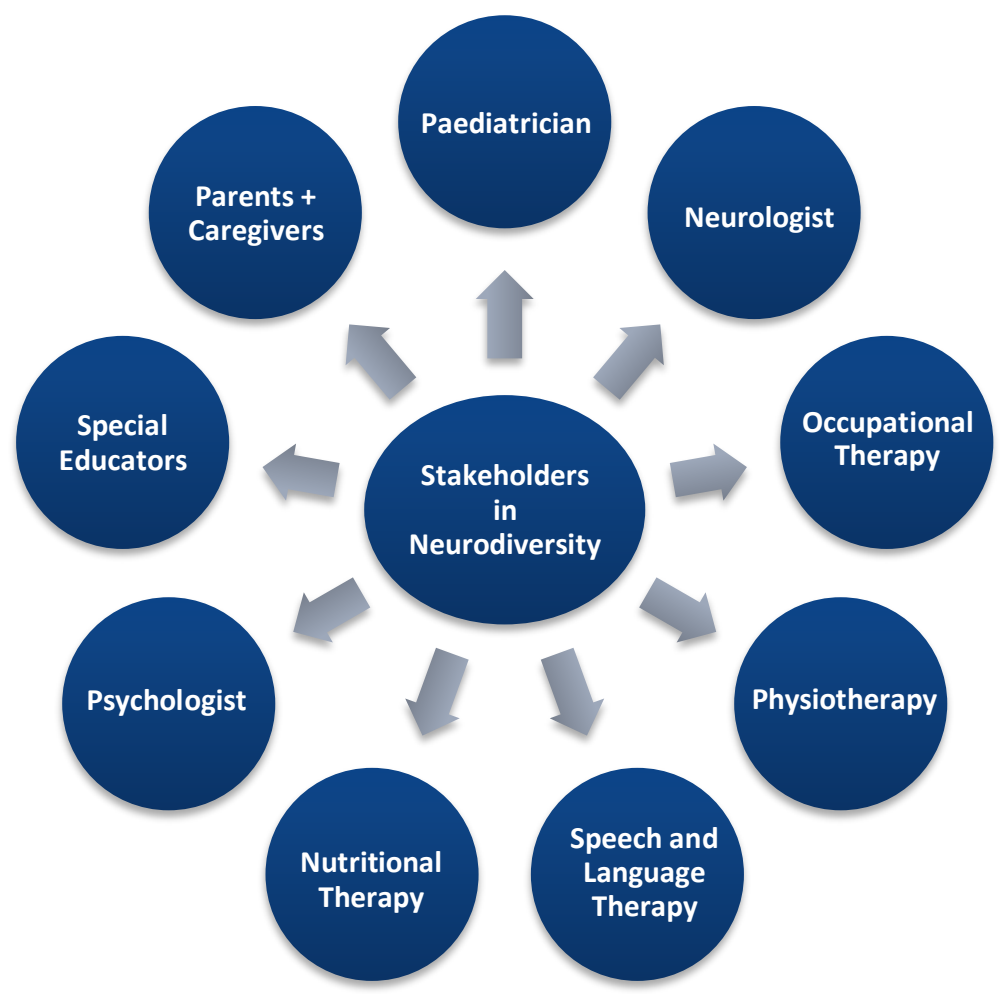

Figure 1.1 Visual representation of stakeholders involved in the neurodiverse support system

\section{Global Healthcare Support Systems}

To understand the existing support systems for the neurodiverse community present in different countries of the world, an in-depth literature search was conducted. Research papers, organizations, support groups, case studies, and innovations were studied and analysed globally to present a concise analysis of the existing support systems for neurodiverse individuals. While some countries/regions displayed advanced healthcare and diversified treatment approaches, many others demonstrated a lack of structure and technical know-how to treat these conditions. Table 1.0 shows a concise summary of the health infrastructure models present across the world, highlighting their progress and gaps simultaneously. 
Table 1.0 Concise Summary of the Existing Support Systems (Problems + Solutions) for Neurodiversity in all Continents

\begin{tabular}{|c|c|c|c|}
\hline Country/Continent & Existing Support System & Persisting Problems & Solutions Suggested/Developed \\
\hline USA & $\begin{array}{l}\text { Numerous foundations, } \\
\text { organisations, societies, } \\
\text { and research groups exist } \\
\text { for helping and supporting } \\
\text { the neurodiverse } \\
\text { community }(20,21,22,23) \\
\text { Financial aid in the form of } \\
\text { grants (58) insurance and } \\
\text { social security benefits are } \\
\text { provided by the } \\
\text { government }(60)\end{array}$ & $\begin{array}{l}\text { Lack of availability of } \\
\text { resources in some regions } \\
\text { of the USA to treat and } \\
\text { support neurodiverse } \\
\text { conditions }(23,24) \\
\text { Low awareness about } \\
\text { neurodiverse conditions in } \\
\text { medical practitioners }(63)\end{array}$ & $\begin{array}{l}\text { Stanford University developed a } \\
\text { mobile platform named "GapMap" } \\
\text { to connect families with local } \\
\text { nearby therapy and support } \\
\text { resources }(25,26,27) \\
\text { USA states adopted the } \\
\text { government Insurance Mandate to } \\
\text { support expenses for ASD, } \\
\text { including out-of-pocket expenses } \\
\text { (28,29) } \\
\text { Behavioural training to increase } \\
\text { the number of Health Care } \\
\text { Providers (HCPs) and state grants } \\
\text { provided to develop well- } \\
\text { coordinated healthcare services } \\
\text { (59) }\end{array}$ \\
\hline Canada & $\begin{array}{l}\text { The government along with } \\
\text { the existence of groups, } \\
\text { organisations, clubs provide } \\
\text { social, educational, } \\
\text { healthcare, and financial } \\
\text { support }(30,31,65)\end{array}$ & $\begin{array}{c}\text { Confusion and low } \\
\text { awareness about } \\
\text { neurodiverse conditions } \\
\text { amidst parents and HCPs } \\
\text { (31) } \\
\text { Delay in diagnosis and long } \\
\text { wait times for required } \\
\text { medical help (31) } \\
\text { The disparity in availability } \\
\text { of services between rural } \\
\text { and urban areas (31) }\end{array}$ & $\begin{array}{c}\text { Social enterprise solutions } \\
\text { developed to increase training and } \\
\text { employment opportunities (66) }\end{array}$ \\
\hline South America & $\begin{array}{l}\text { Few organisations and } \\
\text { conferences take place in } \\
\text { Chile, addressing } \\
\text { neurodiverse issues (68) } \\
\text { Education, financial aid, } \\
\text { healthcare support } \\
\text { provided by a few } \\
\text { organisations in Chile (68) }\end{array}$ & $\begin{array}{c}\text { Low awareness among } \\
\text { parents, less likely to } \\
\text { approach healthcare } \\
(32,68) \\
\text { Long waiting times, } \\
\text { financial burden, and lack } \\
\text { of specialised services } \\
(62,67,68) \\
\text { Stigma about } \\
\text { neurodiversity causes a } \\
\text { delay in diagnosis and } \\
\text { effective therapy }(32,62) \\
\text { Extremely low prevalence } \\
\text { and incidence rates } \\
\text { recorded }(32,68)\end{array}$ & $\begin{array}{l}\text { Learning tools developed and } \\
\text { implemented for assisting children } \\
\text { with ASD in mathematics (69) }\end{array}$ \\
\hline
\end{tabular}




\begin{tabular}{|c|c|c|c|}
\hline UK & $\begin{array}{l}\text { Numerous foundations, } \\
\text { organisations, societies, } \\
\text { and research groups exist } \\
\text { for helping and supporting } \\
\text { the neurodiverse } \\
\text { community (33) } \\
\text { Financial assistance and aid } \\
\text { provided by the } \\
\text { government }(70)\end{array}$ & $\begin{array}{l}\text { Low awareness about } \\
\text { neurodiverse conditions } \\
\text { among parents (34) } \\
\text { Lengthy wait times and } \\
\text { misconceived reporting } \\
\text { during diagnosis }(34,35) \\
\text { No involvement of key } \\
\text { stakeholders (35) } \\
\text { The discrepancy among the } \\
\text { range of services provided } \\
\text { (35) } \\
\text { Poor quality of care (35) } \\
\text { High levels of stress among } \\
\text { parents and caregivers due } \\
\text { to lack of support and } \\
\text { confusion (34,35) } \\
\text { Low levels of health } \\
\text { monitoring for DS (33) }\end{array}$ & $\begin{array}{l}\text { A professional body for GPs } \\
\text { provides resources for the } \\
\text { identification and management of } \\
\text { neurodiverse individuals (34) } \\
\text { Governing bodies train teachers } \\
\text { who work with neurodiverse } \\
\text { individuals to improve the } \\
\text { education system (36) }\end{array}$ \\
\hline $\begin{array}{l}\text { EU (Switzerland, } \\
\text { Netherlands) }\end{array}$ & $\begin{array}{l}\text { Youth and Family Centres } \\
\text { communities help to detect } \\
\text { and treat multiple } \\
\text { neurodiverse conditions } \\
\text { (37) } \\
\text { Financial assistance and aid } \\
\text { provided by the } \\
\text { government (37) }\end{array}$ & $\begin{array}{l}\text { Low support for parents } \\
\text { from therapists }(38,39,40) \\
\text { Rough transition from } \\
\text { paediatric to adult care } \\
\text { facilities }(41) \\
\text { Lack of communication } \\
\text { among medical } \\
\text { practitioners hampering } \\
\text { the overall treatment } \\
\text { process }(41)\end{array}$ & $\begin{array}{l}\text { Development of interactive } \\
\text { robotics assisting autistic children } \\
\text { with social skills (71) }\end{array}$ \\
\hline Africa & $\begin{array}{l}\text { Africa's healthcare system } \\
\text { does not seem well } \\
\text { equipped to manage or } \\
\text { treat neurodiverse } \\
\text { conditions }(42,43,44) \\
\text { No existing support systems } \\
\text { or significant groups for } \\
\text { neurodiverse individuals in } \\
\text { the African continent }(45)\end{array}$ & $\begin{array}{l}\text { Poor levels of awareness } \\
\text { among parents and doctors } \\
\text { and lack of coordination } \\
\qquad(42) \\
\text { Absence of policies and } \\
\text { legislative intimidation } \\
\text { from the government (43) } \\
\text { Lack of coordination, } \\
\text { insufficient resources, low } \\
\text { financial support }(43,44)\end{array}$ & $\begin{array}{l}\text { Research and studies are being } \\
\text { carried out to facilitate treatment } \\
\text { techniques and innovations to } \\
\text { combat the country's barebone } \\
\text { healthcare infrastructure (45) }\end{array}$ \\
\hline $\begin{array}{l}\text { Oceania (Australia, } \\
\text { New Zealand) }\end{array}$ & $\begin{array}{l}\text { Adequate support and } \\
\text { resources in the form of } \\
\text { education, healthcare, } \\
\text { financial aid, and job } \\
\text { protection are offered by } \\
\text { the government and } \\
\text { organisations }(46,47)\end{array}$ & $\begin{array}{l}\text { Inconsistent diagnostic } \\
\text { tests and procedures, lack } \\
\text { of coordination between } \\
\text { stakeholders involved (72) }\end{array}$ & $\begin{array}{l}\text { Technological innovations have } \\
\text { been developed to enable faster } \\
\text { and more efficient ways of support } \\
\text { and treatment for children with } \\
\text { neurodevelopmental conditions } \\
\text { (48). }\end{array}$ \\
\hline
\end{tabular}




\begin{tabular}{|c|c|c|c|}
\hline Asia & $\begin{array}{l}\text { Few small-scale } \\
\text { organizations in ASEAN } \\
\text { countries are present } \\
\text { having limited outreach and } \\
\text { resources }(49,74) \\
\text { The existing support system } \\
\text { is a direct function of } \\
\text { political stability, the } \\
\text { disparity between } \\
\text { development scales of } \\
\text { different Asian countries, } \\
\text { and socio-economic growth }\end{array}$ & $\begin{array}{l}\text { Stigma and lack of } \\
\text { acceptance about } \\
\text { neurodiverse conditions, } \\
\text { both by parents and HCPs } \\
\qquad(50,51) \text {. } \\
\text { Lack of resources and poor } \\
\text { education facilities, poor } \\
\text { accessibility, financial } \\
\text { burden faced by parents } \\
\text { (64,73) } \\
\text { Inconsistent diagnostic and } \\
\text { screenings, discrepancies in } \\
\text { diagnostic criteria leading } \\
\text { to lower prevalence as } \\
\text { compared to Western } \\
\text { counterparts (61) }\end{array}$ & $\begin{array}{c}\text { St. Andrew's auditorium in } \\
\text { Singapore (NPO), specializes in } \\
\text { education, therapy, and care for } \\
\text { patients and families (52) } \\
\text { BehaviorPals, an initiative by } \\
\text { Indonesia offers unbiased support } \\
\text { and treatment strategies for ASD } \\
\text { (73) }\end{array}$ \\
\hline
\end{tabular}

\section{Literature Review of India's Neurodiverse Support System}

Epidemiological studies and research papers were analysed to understand the prevalence and significance of ASD, $C P$, and DS in India. India, being a populous country of 1.3 billion has children $<15$ years as $1 / 3$ of the total world population affected by ASD (8). Estimates from recent studies show that more than 2 million people may have ASD in India (8). For CP, nearly $15-20 \%$ of physically disabled children are affected, having an incidence rate of 3/1000 live births (76). India also reports the highest number of DS cases in the world averaging between 23,000 and 29,000 children every year (77). Most of the data generated in India is from the medical/hospital settings for ASD. There is no data available on the prevalence of this disorder from community settings (8). The high prevalence rates of these neurodevelopmental conditions in India $(8,76,77)$ requires that similar importance should be given to neurological disorders as it to infectious and stress-related non-communicable diseases.

Thus, to understand the present support system in India for treatment and rehabilitation of these conditions, an indepth analysis was conducted from several research papers, excerpts from organizations, and case studies. Gaps were identified in the current support systems that are prevalent in India (75). The list below shows a short synopsis of all the problems and adversities faced by the neurodiverse community and its supporting stakeholders:

- Lack of coordination between parents and doctors (53)

- Low awareness about neurodiverse conditions among parents, doctors, and educators $(54,55)$

- Low accessibility to resources and support $(55,6)$

- High-stress levels for parents and caregivers $(55,6)$

- Huge financial burden $(6,7,57)$

- High levels of stigma, leading to lack of acceptance (56)

- Lesser importance given to parents in the recommendation plan (56)

\section{Aims and Objectives}

Section 1 summarises the concept of neurodiversity along with an in-depth analysis of the global neurodiverse support systems by incorporating the findings from numerous published studies and papers. Thereafter, we decided to conduct a primary research study in Mumbai, India. This qualitative research study was conducted to understand the existing support system present for the neurodiverse community and identify the gaps present in the ecosystem. In the study, the key stakeholders involved in the neurodiverse support system were involved and their existing problems, viewpoints were taken into consideration for our analysis. Based on their responses, recommendations in the form of practical solutions have been suggested at the end of the study

\footnotetext{
${ }^{2}$ Disclaimer: All the information presented in the table has been obtained from a robust literature search conducted on Google Scholar and PubMed. Case studies and research papers have been cited in the table as appropriate. The information cited is completely neutral and unbiased and not indicative of the country/continent's complete existing healthcare infrastructure. There is a possibility of contradicting developments/solutions which could be in place but due to lack of time, financial constraints and publishing restraints, the information has not been included in the table and report.
} 
which can be implemented in real-time, thus improving the quality of the health infrastructure for neurodiverse individuals along with the support services.

\section{Materials and Methods}

Settings: All the stakeholders who participated in our primary research study were from the Western and Eastern suburbs, Central and Harbour division of Mumbai.

Eligibility Criteria and Sample Size; For our study, stratified random sampling was performed in selecting the following stakeholders wherein each group had a sample size of $10(n=10)$, total sample size: $n=50$, and the participants were from one of the following professional fields:

1. Paediatrics (Developmental/ Paediatric Neurologist/ General)

2. Therapists (Occupational, Speech, Physio)

3. Psychologists/ Psychiatrists/ABA

4. Academics (Special Educators/Remedial Teachers/School Counsellors)

5. Parents of children with neurological conditions (Age: 2-13 years)

Recruitment, Enrolment, and Consent Methods; Initially, the prospective participants were contacted over text/email and a brief introduction of the research study was provided to them. After receiving their agreement (via text), a time slot was fixed upon wherein the interview would be conducted. All interviews were conducted over the phone in English either as Zoom audio calls or normal telephonic calls (according to the participant's preference).

Questionnaires; For each participant group, an independent questionnaire (included in appendix) was created and information was collected based on the experiences of participants (professional stakeholders) as well as the parents.

Statistical analysis; All graphs were produced in Microsoft Excel. All statistical analyses have been carried out using the one-tailed $z$ test wherein the test proportion was chosen as 0.5 ( $50 \%$ was chosen as the majority limit for all the parameters to show a statistically significant result which was chosen as the null hypothesis). All the parameters which showed $p$-value $\geq 0.05$ were chosen to be relevant for all the datasets as there was insufficient evidence to reject the null hypothesis.

\section{$\underline{\text { Results }}$}

Research findings on the medical community and experiences

The cohort groups of medical professionals (paediatricians, therapists, and psychologists) were collated together $(n=30)$ and the research findings are shown below. Among the academic professionals interviewed $(n=10), 50 \%$ worked in regular schools, $20 \%$ in special schools, and $30 \%$ in private centres. The parent group interviewed for the research study $(n=10)$ had a mix of working parents $(50 \%)$ and homemakers $(50 \%)$. All of the respondents had children with either one or multiple conditions as follows: (ASD, CP, ADHD, epilepsy, learning disabilities, speech impairment, Rett's Syndrome) with the average age of the child being 8 years. For some of the parameters, similar questions were asked to the academic cohort group in which, along with the other stakeholders involved for which $\mathrm{n}=40$. With an average of 17 new cases per month among medical professionals, $80 \%$ ( $p$-value $=0.99,>0.05$ ) of all professionals (including academic professionals) stated that the ratio of males is higher as compared to females.

First Point of Contact (POC)

As stated by $50 \%$ ( $p$ value $=0.5,>0.05$ ) medical respondents (Fig. 1.2) ( $n=30)$, the paediatricians are the first POC for parents of children with neurological conditions. For the academic sector $(n=10), 60 \%$ ( $p$ value $=0.73,>0.05)$ of the respondents (Fig.1.3) stated that the first point of academic intervention is the regular school/class teacher. For the parent cohort group interviewed $(n=10), 40 \%$ ( $p$ value $=0.26,>0.05$ ) of the respondents stated that the paediatrician was their first POC (Fig.1.4).

Figure 1.2 First POC for medical intervention;

Figure 1.3 First POC for academic intervention; 


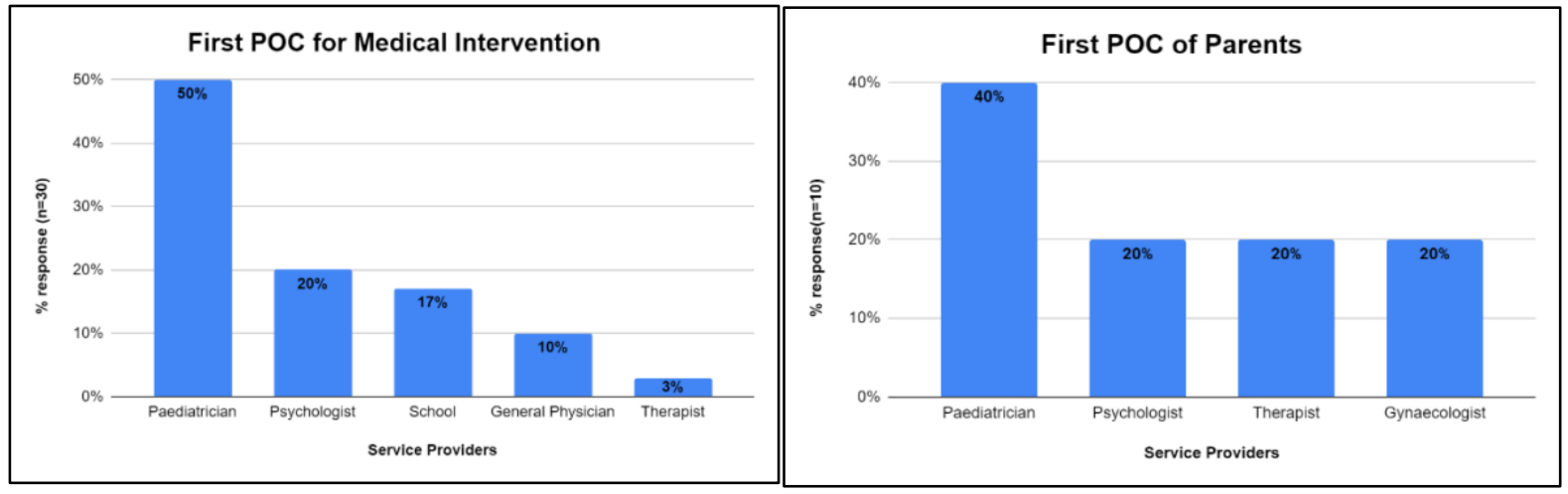

Figure 1.4 First POC of parents

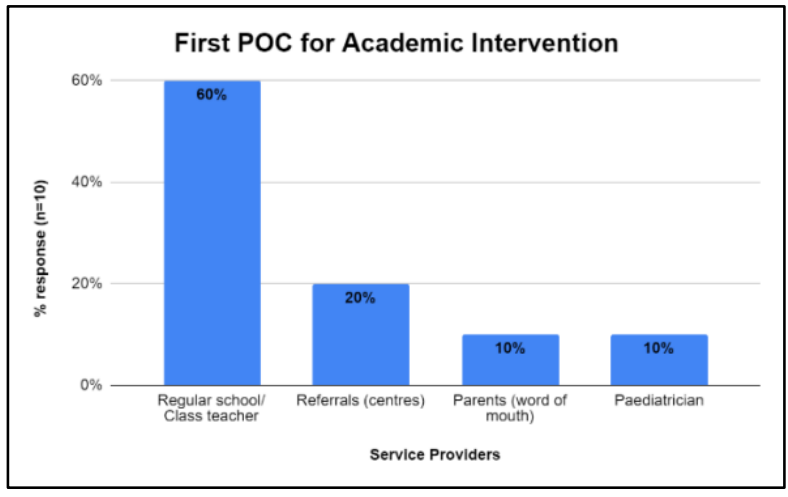

\section{Initial Symptoms}

For each cohort group, the initial symptoms remained constant throughout all 10 of the respondents' responses. The paediatricians stated delayed milestones, behavioural issues, low communication, and socialization as the primary noticeable sign. Therapists interviewed stated speech delay, low socialization, and delayed milestones as the primary concern of the parents. Psychologists stated academic, behavioural, and socialization issues as initial signs. The academic professionals stated academic, concentration, and behavioural issues as the primary concern. $57 \%$ ( $p$-value $=0.67,>0.05$ ) of the parents stated delayed milestones in their child as the first noticeable symptom that prompted them to visit a medical professional (Fig. 1.5). One respondent stated: "as parents, we missed out many of the developmental milestones which we should have known..."

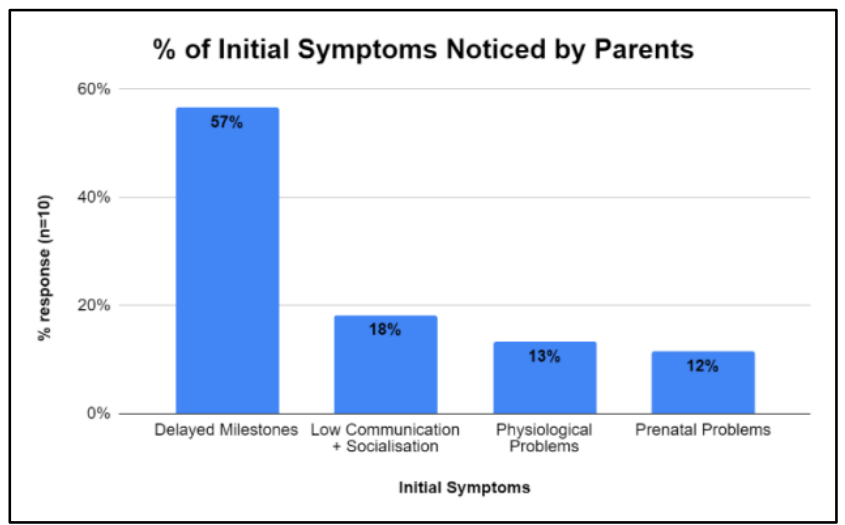

Figure 1.5 Representation of initial symptoms noticed by parents

\section{Levels of Knowledge in Families}


The respondents $(43 \%, p$-value $=0.22,>0.05)$ of the medical cohort reported that they felt that the parents had extremely low levels of knowledge and termed the parents as "Google parents" (Fig.1.6), with 80\% ( $p$-value = $0.97,>0.05$ ) of paediatricians stating that lack of acceptance is the primary reaction of the parents on finding out about the condition/disorder from the medical professionals. Out of all 10 parent respondents, $70 \%$ ( $p$-value = $0.89,>0.05$ ) of the parents interviewed stated that they had low to almost no knowledge of the disorder/condition before visiting a medical professional (Fig.1.7). The medical cohort group (97\%, p-value $=0.99,>0.05$ ) stated that the families of children with neurological conditions had high levels of stigma attached to the therapy visits with $75 \%$ ( $p$ value $=0.98,>0.05$ ) mentioning that the families hid the therapy visits from their extended families. Some of the parents shared interesting insights on how they would navigate this as "grandparents dissuaded therapy and counselling" thus making them call the therapy sessions "play-time" or refer to the therapists as "play aunty".
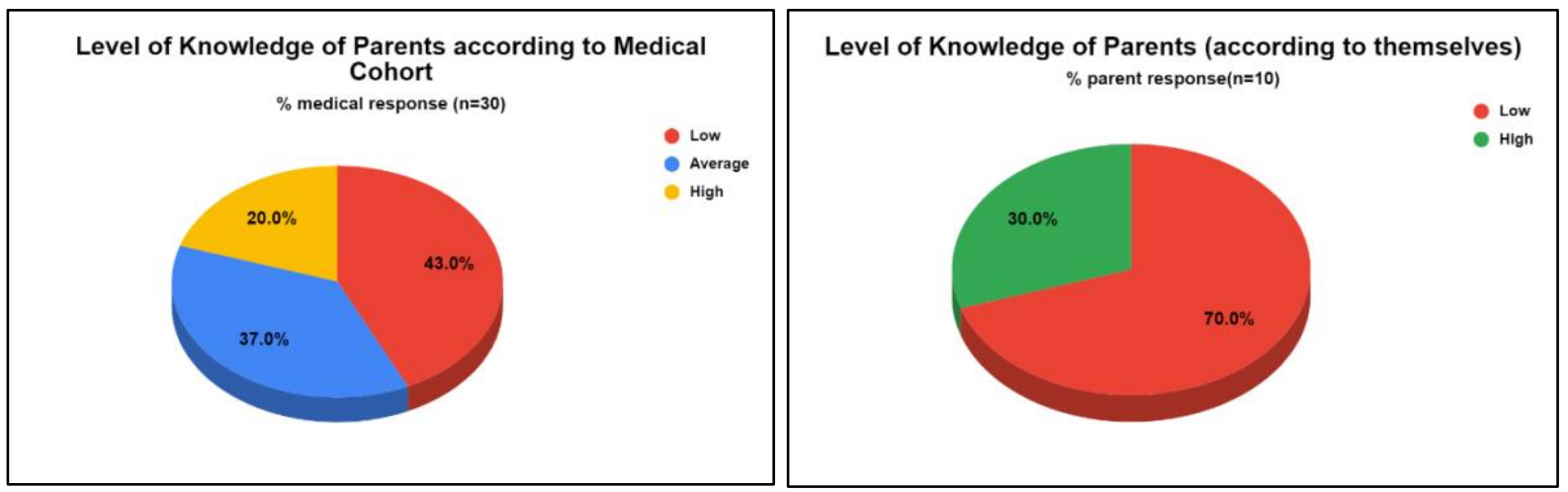

Figure 1.6 Knowledge of parents as stated by medical cohort Figure 1.7 Knowledge on neurodiversity as stated by parents

\section{Support System}

The level of support and understanding between the medical community and parents was understood by the following parameters. $70 \%$ ( $p$-value $=0.89,>0.05$ ) of the parents took 18 months or more from identifying the first symptom to receiving an accurate diagnosis (Fig.1.8). $60 \%$ ( $p$-value $=0.73,>0.05$ ) of the parent respondents stated that they changed 3 or more service providers before receiving an accurate diagnosis (Fig.1.9). This was supported by the results from $80 \%$ ( $p$-value $=0.97,>0.05$ ) of the parent respondents feeling unsatisfied with the quality of the support received during the entire diagnosis and treatment process (Fig.2.0).
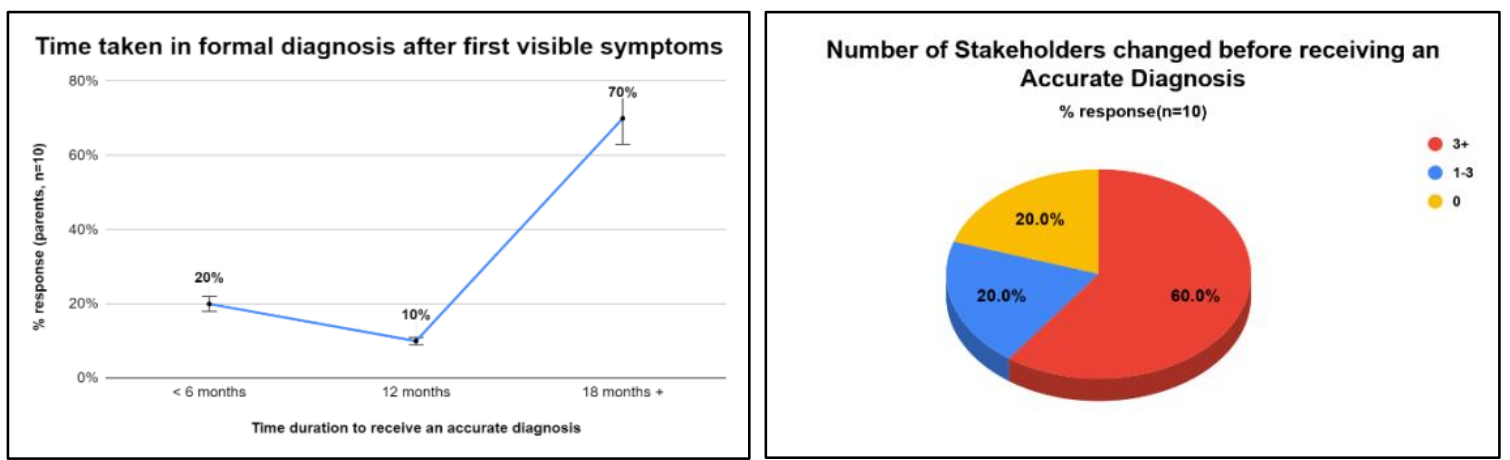

Figure $1.8 \%$ representation of time intervals by parents Figure 1.9 Number of stakeholders changed for a formal diagnosis 
Satisfaction in Support Received during Diagnosis $\%$ response $(n=10)$

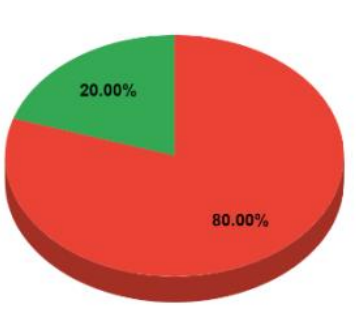

Satisfled

Figure 2.0 Support satisfaction levels by parent

respondents

\section{Therapy Planning and Approach}

$53 \%(p$-value $=0.64,>0.05)$ of all professionals interviewed (medical + academic) stated that they collected and stored data only in non-digital format (Fig.2.1). In the academic cohort group, $50 \%$ ( $p$-value $=0.5,>0.05)$ of the respondents stated that they used IEPs (Individualized Education Plans), ICPs (Individualized Counselling Plans), and PCPs (Person-Centred Plans) for their neurodiverse students (Fig.2.2)

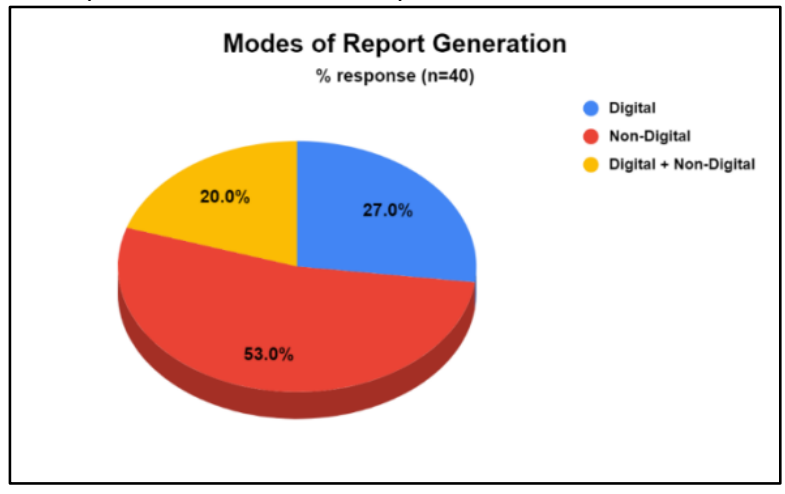

Figure 2.1 Modes of report generation by stakeholders

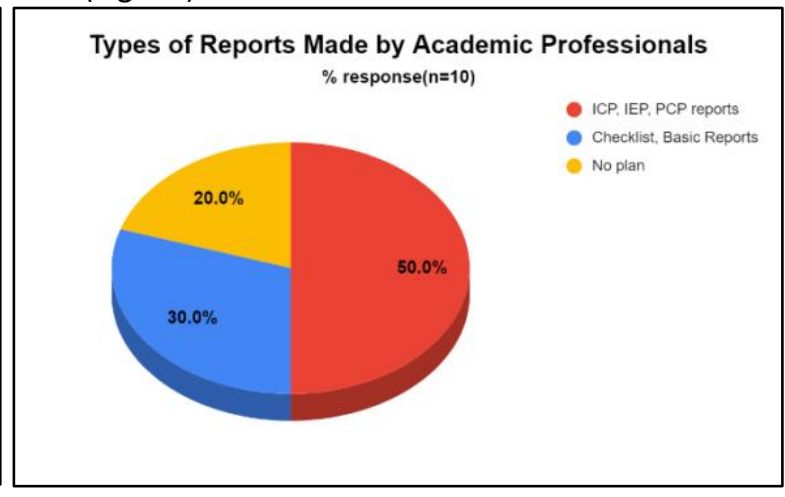

Figure 2.2 Types of reports by academic respondents

When asked about their modes of communication, 35\% ( $p$-value $<0.05$ ) of all professional respondents stated that they used phone calls to coordinate with the other stakeholders, while $25 \%$ ( $p$-value $<0.05$ ) of the professionals stated that there was no coordination at all between them (Fig.2.3). 50\% ( $p$-value $=0.5,>0.05$ ) of the medical respondents stated that the level of coordination among stakeholders is extremely poor in India, and there lies a high scope for improvement (Fig.2.4). These results were supported by $70 \%$ ( $p$-value $=0.89,>0.05$ ) of the paediatricians stating that there is poor to no coordination between them and other stakeholders (therapists, psychologists, special educators). However, in terms of coordination of the service providers, $90 \%$ ( $p$-value = $0.99,>0.05$ ) of the parents stated: "we act as connections for the therapists and doctors. We share reports from one service provider to another"

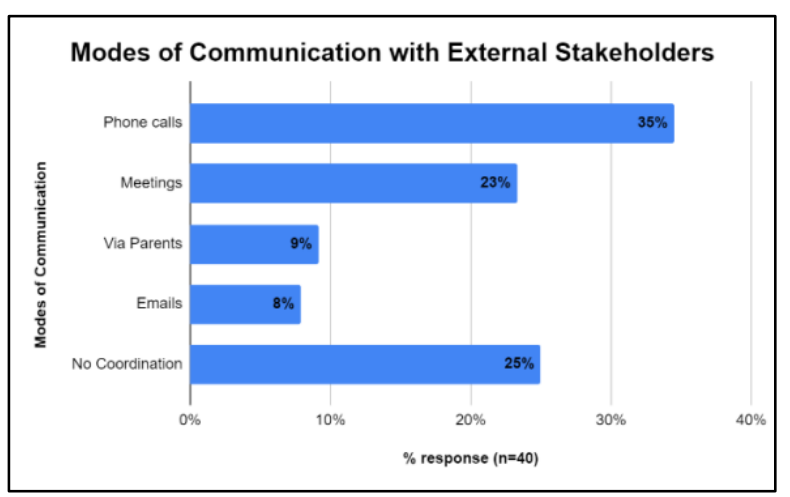

Figure 2.3 Modes of communication with stakeholders

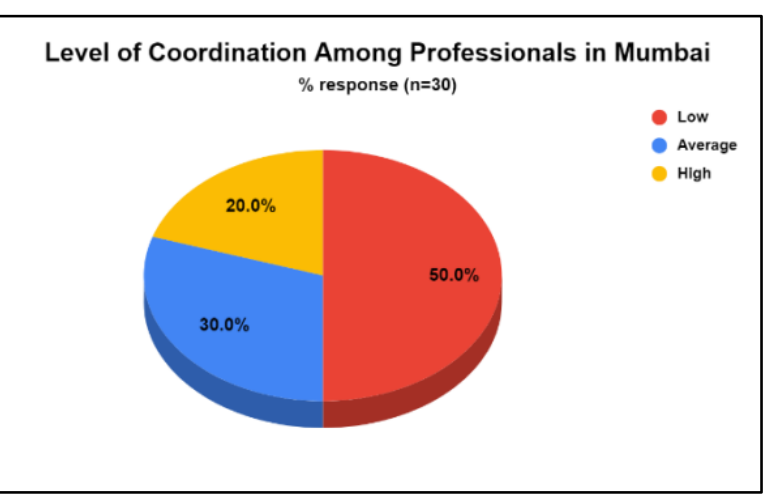

Figure 2.4 Level of coordination in Mumbai 
Furthermore, $90 \%$ ( $p$-value $=0.99,>0.05)$ of paediatric respondents stated that on transitioning into adulthood the change in the support system was extremely stressful for the child and could account for being a source of trauma. One paediatrician also mentioned the need for transitory clinics/setups in India which could aid the process for parents and children alike.

\section{$\underline{\text { Recommendation Plan }}$}

$30 \%$ ( $p$-value $<0.05$ ) of the medical respondents consider "severity of the case" as a factor while making the recommendation plan along with $19 \%$ ( $p$-value $<0.05$ ) considering "parental involvement" (Fig.2.5). These findings are similar to the findings from the secondary research (56), wherein the level of parents' involvement was poor while drafting a recommendation plan.

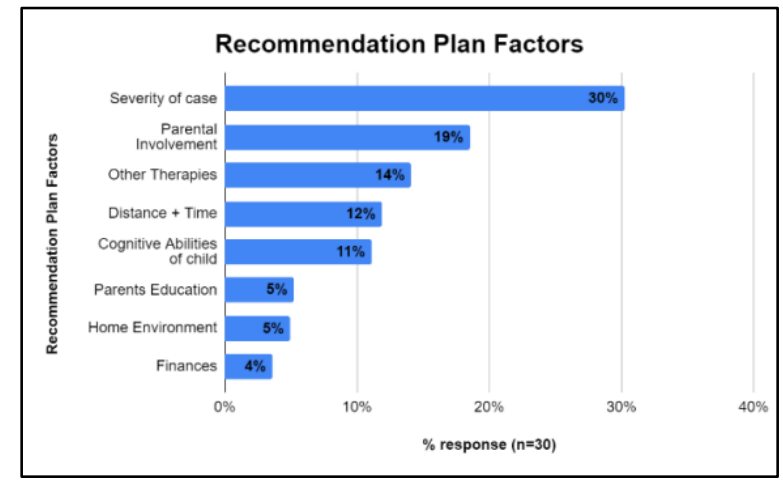

Figure 2.5 Factors used by stakeholders for recommendation plans

\section{Challenges and Drawbacks}

As stated by the respondents, the challenges and drawbacks were similar to the findings from the secondary research $(53,54,55,56)$. The medical respondents stated that the main reasons for lack of early intervention (EI) in Mumbai are: low awareness about the conditions (34\%) (p-value <0.05) (Fig.2.6) and the lack of acceptance in parents (32\%) ( $p$-value $<0.05)$. This was supported by $18 \%$ ( $p$-value $<0.05)$ and $16 \%$ ( $p$-value $<0.05$ ) of the medical respondents stating that the absence of a multi-disciplinary approach and low awareness in parents are the two main challenges faced in the healthcare system (Fig.2.7). This $18 \%$ consisted of the entire paediatric respondents wherein all $100 \%$ ( $p$-value $=0.99,>0.05)$ of the paediatricians $(n=10)$ highlighted the need for a multidisciplinary approach. $67 \%(p$ value $=0.96,>0.05$ ) of the medical respondents stated that the level of knowledge about neurodiverse conditions was low in medical professionals (Fig.2.8) and there is a need to create awareness about the same.
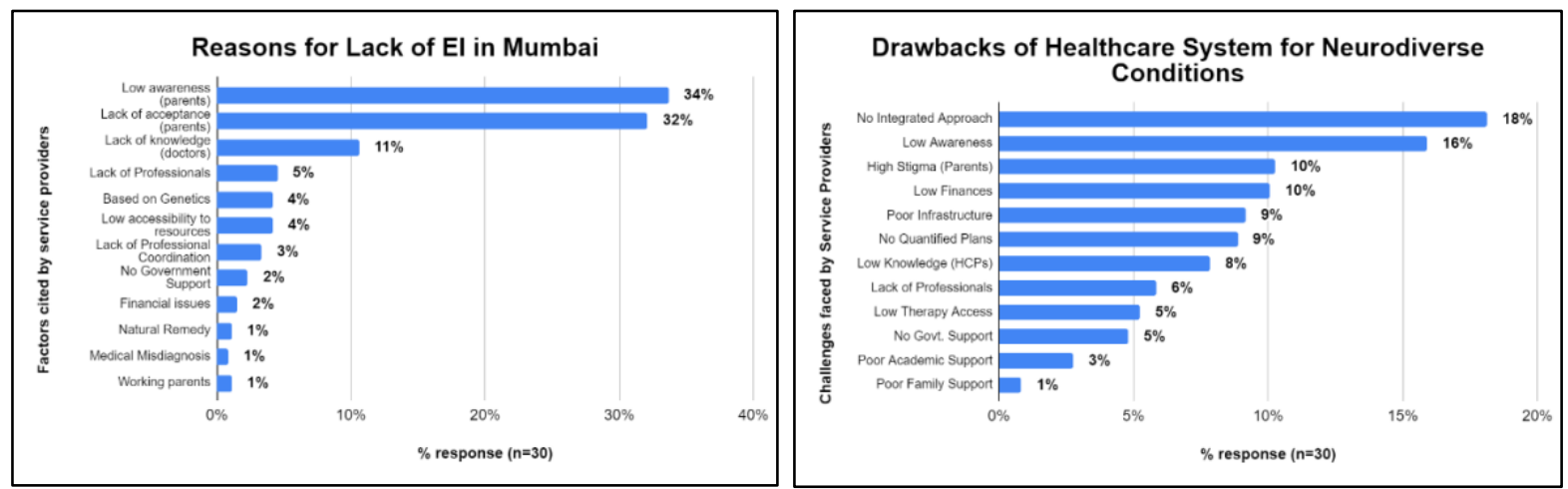

Figure 2.6 Reasons for Lack of El in Mumbai

Figure 2.7 Drawbacks of the Healthcare System in Mumbai 


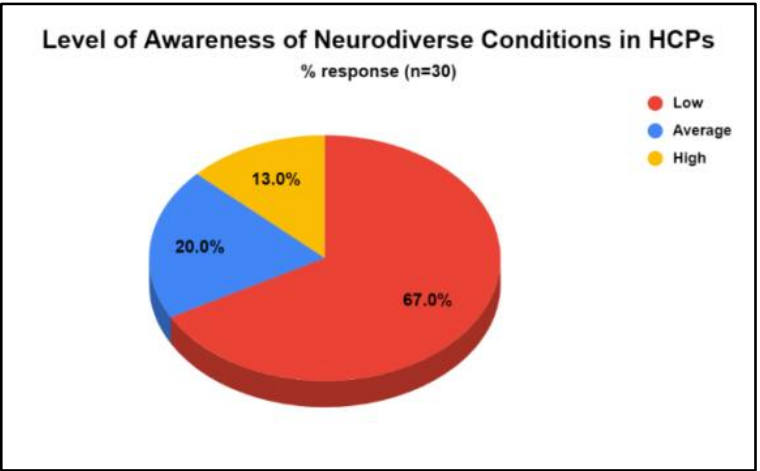

Figure 2.8 Representation of medical respondents' perception of knowledge levels of neurodiverse conditions in HCPs

In the education sector, $50 \%$ ( $p$-value $=0.5,>0.05$ ) of the respondents felt that the level of inclusivity in the education sector is still very poor (Fig.2.9), and there lies a scope for improvement. Some of the responses included: "the level of inclusiveness in the government-aided schools is almost nothing" "many schools say they are inclusive but don't provide any kind of support later on". $29 \%$ ( $p$-value $=0.09,>0.05$ ) of the academic respondents stated low awareness among the teachers to be the primary challenge (Fig.3.0). In terms of parent respondents, $26 \%(p$-value $=0.06,>0.05$ ) mentioned a lack of awareness about the condition to be a significant challenge that they faced (Fig.3.1). Furthermore, $40 \%$ ( $p$-value $=0.26,>0.05$ ) of the parents have no financial planning and health insurance kept in place for their child (Fig.3.2).

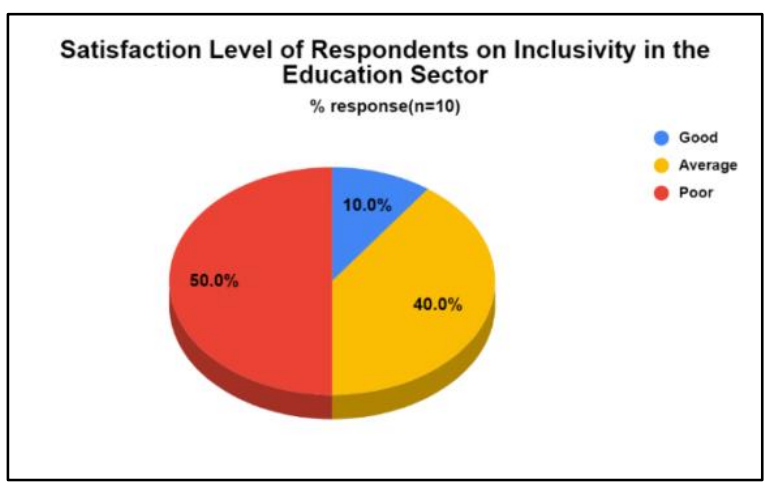

Figure 2.9 Level of inclusion in the education sector

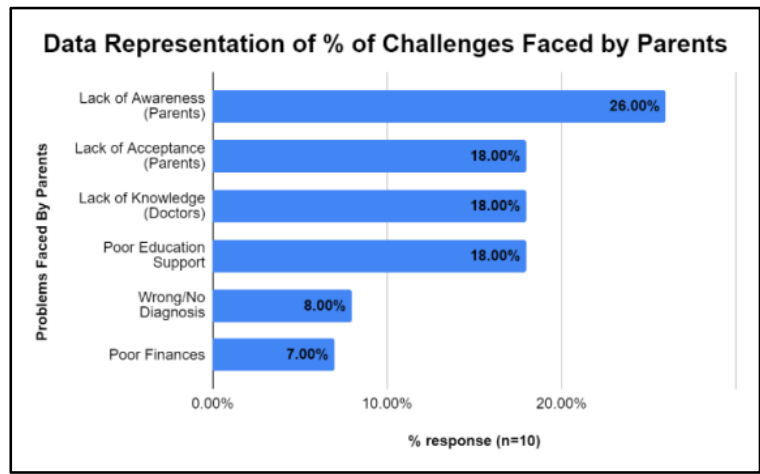

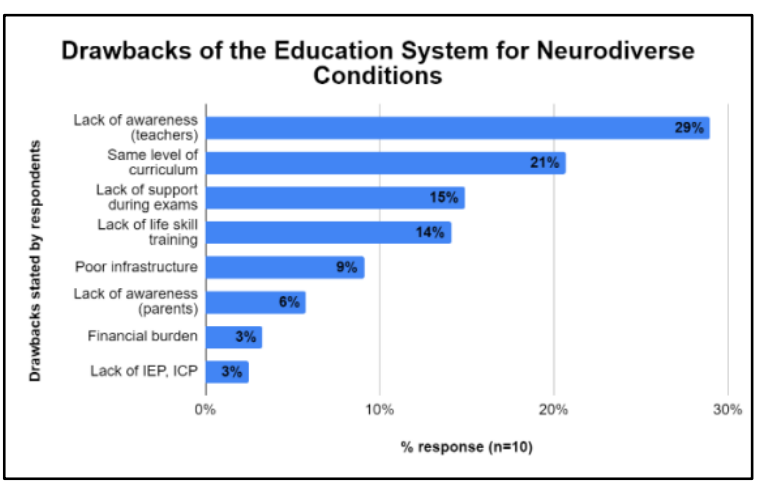

Figure 3.0 Drawbacks of the education system

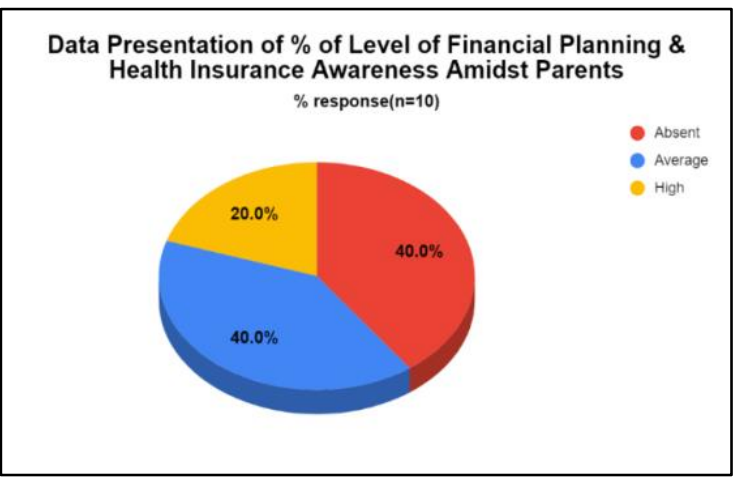

Figure 3.1 Challenges faced by parents in the diagnostic journey Figure 3.2 Level of financial planning by parents

\section{Discussion}

Analysis and evaluation of the results obtained showed that there are significant gaps in the health infrastructure for the neurodiverse community in Mumbai, India. The points highlighted the areas of improvement and the urgent need to bring about a change in specific areas of the support systems as discussed below: 


\section{Requirement for a Well-Coordinated Multidisciplinary Platform}

As obtained from the results above which are synchronous with the analysis made (Section 1.5) from review papers (53), lack of coordination amongst parents, service providers, and different stakeholders of the support system present to be as one of the main challenges. With the paediatricians highlighting the absence of a multidisciplinary platform, followed by the parent respondents stating that they take up the role of coordinators, an up-to-date systematic platform will aid in facilitating better connectivity and synergy between all the stakeholders and the parents. Paediatricians and teachers who have been identified as the primary POC for children with special needs should be updated with the progress of their child/patient too. Having well-documented reports on an integrated platform serves as a reliable source for references for service providers and parents in the future. Thus, this underlines the urgent need for developing a comprehensive multidisciplinary platform, wherein all the stakeholders including the primary caregivers are well updated and work collaboratively in the diagnostic process of the child.

\section{External Unbiased Source of Support}

Stigma leading to a lack of acceptance thus inducing high levels of stress in parents/primary caregivers is widely prevalent amidst the participants interviewed as well as observed from the literature review analysis $(6,55,56)$. This stigma often leads to the families living in denial in-spite of observing the symptoms, leading to a delay in diagnosis. Due to this topic being a taboo in many households, hiding therapy visits emerged as one of the strong findings in this study. This was supported by the results that showed a lack of acceptance of the diagnosis by the parents followed by statements that indicated them not feeling supported enough in the entire diagnostic journey. Hence, it is necessary to understand the significance of constant support for the parents; providing counselling and assistance in diagnostic and financial matters. Financial planning $(6,7,57)$ and therapy plans are not thought through by the parents (as also observed from the literature review analysis) and are instead thrust upon by the service providers which proves to be detrimental for their diagnostic journey. The results of this study showed that a majority of the paediatric respondents felt that the transitioning journey from a paediatric setup to an adult environment, thus changing all the therapies, HCPs, support staff involved could be extremely traumatic for children with special needs. This highlights the importance and needs for an external consistent and unbiased source of support for both the parents as well as the children providing the right kind of guidance, advice, and hand-holding.

\section{Technology-Based Sustainable Data-Driven Plans}

As observed from the results, non-digital versions of reports are still being created and implemented amidst the majority of the stakeholders involved. The results showed that ICPs, IEPs are used in the academic setting by the majority of the respondents demonstrating a good understanding of data-driven processes with a goal-centred approach. However, as the conversation proceeded it was brought to notice that these plans were not followed through until the end of the academic year with the students. Thus, there lies an immediate need for strengthening these processes. Sustainable consistent technology-based data supported plans will help in easing the processes and ensure no firefighting techniques are utilized by the professionals involved by the service providers in the support system.

\section{Well Researched and Vetted Resource Centre}

Lack of knowledge about neurodevelopmental conditions leads to a lack of acceptance. Thus, to bring about a change in the awareness levels it is important to educate all the stakeholders involved along with the primary caregivers. The results obtained show that the level of knowledge about these conditions/disorders is low among parents, medical service providers as well as teachers. This is similar to the findings from the gaps identified in the literature review $(54,55)$. In the academic sector, it is mainly the lack of awareness that leads to poor inclusivity of children with special needs in regular schools. These points highlight the need for developing a knowledge-driven resource centre that would provide support to the parents, academic and medical community consistently. Parents being referred to as "Google parents" also focus on the importance of providing genuine factual information, thus reducing the dependency on the internet. Being a vetted resource centre, parents can also verify facts and observed symptoms in their child from this centre thus driving away any kind of doubts or confusion. It is, thus, important to have a trusted and real-time knowledge base that shall provide support to the stakeholders and the caregivers involved.

\section{Ease of Accessibility to Therapy and Resources}

Low accessibility to therapy, support, and resources was observed in the results obtained above and correlated with the findings from the literature reviews $(6,55)$ too. Changing multiple service providers and having an extended 
timespan in getting a formal diagnosis too proved to be evidence markers of the previous statement. This shows the need for developing a resource platform that primary caregivers can easily use and access. As observed from the results, there still exists a form of confusion in the parents on "Whom to visit first?" "Which doctor would be the correct choice for my child?", "What is the next step in the diagnostic journey?". It is necessary to conduct further research and come up with a strong innovative solution that will enable the parents to have better knowledge and accessibility to all therapy and medical resources needed for their child.

\section{Limitations}

First, the small sample size is based only in Mumbai and not inclusive of all the conditions which fall under the umbrella term of "neurodiversity". Second, the lack of standardized and validated research survey questions/tools that specifically focus on the prevalence and healthcare support systems was not available for use for all the cohort groups. Third, due to a wide range of parameters chosen for the primary research study, a vast expansive secondary research for all the global support systems could not be conducted due to time and financial constraints.

\section{Conclusion}

Overall, this research study highlights the global healthcare support systems for neurodiverse conditions, providing a brief concise summary of all the continents present. Furthermore, significant problems existing in the current healthcare system and support services for the treatment and rehabilitation of neurodiverse conditions have been identified. Several key solutions have been suggested which could be implemented for improving the quality of the services provided and aid coordination between the different stakeholders and primary caregivers. This study highlights that there are not many high quality epidemiological based research studies on neurodevelopmental conditions in India. Thus, further research in these areas will encourage the development of evidence-based solutions for mitigating the problems faced by neurodiverse community along with the support system in India.

\section{Conflict of Interest}

The authors have no conflicting interests with any external or internal sources and do not have anything to disclose.

\section{References}

1. Robertson SM. Neurodiversity, quality of life, and autistic adults: Shifting research and professional focuses onto real-life challenges. Disability Studies Quarterly. 2009 Dec 14;30(1).

2. https://www.understood.org/en/friends-feelings/empowering-your-child/building-onstrengths/neurodiversity-what-you-need-to-know

3. Kapp, S.K., Gillespie-Lynch, K., Sherman, L.E. and Hutman, T., 2013. Deficit, difference, or both? Autism and neurodiversity. Developmental psychology, 49(1), p.59.

4. Baron-Cohen S. Editorial Perspective: Neurodiversity-a revolutionary concept for autism and psychiatry. Journal of Child Psychology and Psychiatry. 2017 Jun;58(6):744-7.

5. https://www.geniuswithin.co.uk/information/

6. Jain A, Ahmed N, Mahour P, Agarwal V, Chandra K, Srivastava NK. Burden of care perceived by the principal caregivers of autistic children and adolescents visiting health facilities in Lucknow City. Indian Journal of Public Health. 2019 Oct 1;63(4):282.

7. Duggal C, Dua B, Chokhani R, Sengupta K. What works and how: Adult learner perspectives on an autism intervention training program in India. Autism. 2020 Jan 1:1362361319856955.

8. Chauhan A, Sahu JK, Jaiswal N, Kumar K, Agarwal A, Kaur J, Singh S, Singh M. Prevalence of autism spectrum disorder in Indian children: a systematic review and meta-analysis. Neurology India. 2019 Jan 1;67(1):100.

9. https://www.ninds.nih.gov/Disorders/All-Disorders/Cerebral-Palsy-Information-Page

10. https://www.cerebralpalsy.org/about-cerebral-palsy/definition

11. https://www.healthline.com/health/down-syndrome

12. Rosser TC, Edgin JO, Capone GT, Hamilton DR, Allen EG, Dooley KJ, Anand P, Strang JF, Armour AC, FrankCrawford MA, Channell MM. Associations between medical history, cognition, and behavior in youth with down syndrome: a report from the down syndrome cognition project. American journal on intellectual and developmental disabilities. 2018 Nov;123(6):514-28.

13. Weijerman ME, de Winter JP. Clinical practice. The care of children with Down syndrome. Eur J Pediatr. 2010;169(12):1445-1452.

14. https://www.nichd.nih.gov/health/topics/down/conditioninfo/treatments 
15. https://www.cerebralpalsyguide.com/cerebral-palsy/types/

16. https://www.ninds.nih.gov/Disorders/Patient-Caregiver-Education/Hope-Through-Research/CerebralPalsy-Hope-Through-Research

17. https://www.nichd.nih.gov/health/topics/cerebral-palsy/conditioninfo/treatments

18. https://my.clevelandclinic.org/health/diseases/17818-down-syndrome/management-and-treatment

19. https://www.cdc.gov/ncbddd/autism/treatment.html

20. https://www.globalautismproject.org/

21. https://www.autismspeaks.org/

22. https://www.autism-society.org/

23. Gordon-Lipkin E, Foster J, Peacock G. Whittling down the wait time: exploring models to minimize the delay from initial concern to diagnosis and treatment of autism spectrum disorder. Pediatric Clinics. 2016 Oct 1;63(5):851-9.

24. Williams K, Wargowski D, Eickhoff J, Wald E. Disparities in health supervision for children with down syndrome. Clinical pediatrics. 2017 Dec;56(14):1319-27.

25. Ning M, Daniels J, Schwartz J, Dunlap K, Washington P, Kalantarian H, Du M, Wall DP. Identification and Quantification of Gaps in Access to Autism Resources in the United States: An Infodemiological Study. Journal of medical Internet research. 2019;21(7):e13094.

26. Albert N, Daniels J, Schwartz J, Du M, Wall DP. GapMap: enabling comprehensive autism resource epidemiology. JMIR public health and surveillance. 2017;3(2):e27.

27. Daniels J, Schwartz J, Albert N, Du M, Wall DP. The GapMap project: a mobile surveillance system to map diagnosed autism cases and gaps in autism services globally. Molecular autism. 2017 Dec;8(1):55.

28. Candon MK, Barry CL, Marcus SC, Epstein AJ, Kennedy-Hendricks A, Xie M, Mandell DS. Insurance Mandates and Out-of-Pocket Spending for Children With Autism Spectrum Disorder. Pediatrics. 2019 Jan 1;143(1):e20180654.

29. Callaghan T, Sylvester S. Autism spectrum disorder, politics, and the generosity of insurance mandates in the United States. PloS one. 2019;14(5).

30. https://www.ontario.ca/page/ontario-autism-program

31. Smith-Young J, Chafe R, Audas R. "Managing the Wait": Parents' Experiences in Accessing Diagnostic and Treatment Services for Children and Adolescents Diagnosed With Autism Spectrum Disorder. Health Services Insights. 2020 Jan;13:1178632920902141.

32. Zuckerman KE, Sinche B, Cobian M, Cervantes M, Mejia A, Becker T, Nicolaidis C. Conceptualization of autism in the Latino community and its relationship with early diagnosis. Journal of developmental and behavioral pediatrics: JDBP. 2014 Oct;35(8):522.

33. Kageleiry A, Samuelson D, Duh MS, Lefebvre P, Campbell J, Skotko BG. Out-of-pocket medical costs and third-party healthcare costs for children with Down syndrome. American journal of medical genetics Part A. 2017 Mar;173(3):627-37.

34. Crane L, Batty R, Adeyinka H, Goddard L, Henry LA, Hill EL. Autism diagnosis in the United Kingdom: Perspectives of autistic adults, parents and professionals. Journal of autism and developmental disorders. 2018 Nov 1;48(11):3761-72.

35. Care Quality Commission. Health care for disabled children and young people. A review of how the health care needs of disabled children and young people are met by the commissioners and providers of health care in England. 2012.

36. https://www.autism.org.uk/

37. Van't Hof M, van Berckelaer-Onnes I, Deen M, Neukerk MC, Bannink R, Daniels AM, Hoek HW, Ester WA. Novel insights into autism knowledge and stigmatizing attitudes toward mental illness in Dutch youth and family center physicians. Community mental health journal. 2020 Feb 11:1-3.

38. Carlsson E, Miniscalco C, Kadesjö B, Laakso K. Negotiating knowledge: Parents' experience of the neuropsychiatric diagnostic process for children with autism. International journal of language and communication disorders. 2016 May;51(3):328-38.

39. Arnadottir U, Egilson ST. Evaluation of therapy services with the Measure of Processes of Care (MPOC-20): The perspectives of Icelandic parents of children with physical disability. Journal of Child Health Care. 2012 Mar;16(1):62-74.

40. Alsem MW, Verhoef M, Gorter JW, Langezaal LC, Visser-Meily JM, Ketelaar M. Parents' perceptions of the services provided to children with cerebral palsy in the transition from preschool rehabilitation to schoolbased services. Child: care, health and development. 2016 Jul;42(4):455-63. 
41. Van den Driessen Mareeuw FA, Coppus AM, Delnoij DM, de Vries E. Quality of health care according to people with Down syndrome, their parents and support staff-A qualitative exploration. Journal of Applied Research in Intellectual Disabilities. 2020 May;33(3):496-514.

42. Gona JK, Newton CR, Rimba KK, Mapenzi R, Kihara M, Vijver FV, Abubakar A. Challenges and coping strategies of parents of children with autism on the Kenyan coast. Rural and remote health. 2016 Apr;16(2):3517.

43. Khalil M, Elweshahy H, Abdelghani H, Omar T, Ahmed S. Quality of care provided to children with cerebral palsy, Alexandria, Egypt. Eastern Mediterranean Health Journal. 2018;24(6):522-31.

44. Kyeremateng JD, Edusei A, Dogbe JA, Opoku MP, Nketsia W, Hammond C, Afriyie SA. Experiences of primary caregivers of children with cerebral palsy across the trajectory of diagnoses in Ghana. African Journal of Disability. 2019;8. (Africa)

45. Wannenburg N, van Niekerk R. Early diagnosis and intervention for autism spectrum disorder in Africa: insights from a case study. African health sciences. 2018;18(1):137-46.

46. https://www.autismspectrum.org.au/about-aspect/who-we-are

47. https://www.autismnz.org.nz/about-us/about-autism-new-zealand/

48. https://www.createdigital.org.au/screening-cerebral-palsy-via-app-creates-more-opportunities-remotehealthcare/

49. http://autismchina.org/english/index.htm

50. Heys M, Alexander A, Medeiros E, Tumbahangphe KM, Gibbons F, Shrestha R, Manandhar M, Wickenden $M$, Shrestha M, Costello A, Manandhar D. Understanding parents' and professionals' knowledge and awareness of autism in Nepal. Autism. 2017 May;21(4):436-49.

51. Liu Y, Li J, Zheng Q, Zaroff CM, Hall BJ, Li X, Hao Y. Knowledge, attitudes, and perceptions of autism spectrum disorder in a stratified sampling of preschool teachers in China. BMC psychiatry. 2016 Dec;16(1):142.

52. https://www.saac.org.sg/index.php

53. Ellias SD, Shah HR. A study of assessment of knowledge of childhood autism among medical students in Mumbai. Annals of Indian Academy of Neurology. 2019 Apr;22(2):164.

54. Mendonsa LE, Tiwari S. A Survey of Knowledge and Beliefs regarding Autism in Speech-Language Pathologists in India. Folia Phoniatrica et Logopaedica. 2018;70(3-4):191-202.

55. Mahapatra P, Pati S, Sinha R, Chauhan AS, Nanda RR, Nallala S. Parental care-seeking pathway and challenges for autistic spectrum disorders children: A mixed method study from Bhubaneswar, Odisha. Indian journal of psychiatry. 2019 Jan;61(1):37.

56. Minhas A, Vajaratkar V, Divan G, Hamdani SU, Leadbitter K, Taylor C, Aldred C, Tariq A, Tariq M, Cardoza $P$, Green J. Parents' perspectives on care of children with autistic spectrum disorder in South Asia-Views from Pakistan and India. International Review of Psychiatry. 2015 May 4;27(3):247-56

57. https://www.livemint.com/insurance/news/for-autism-treatment-insurance-an-issue1554527294789.html

58. http://www.autismsupportnetwork.com/resources/category/grants

59. https://www.hhs.gov/programs/topic-sites/autism/autism-support/index.html

60. https://www.autismspeaks.org/financial-autism-support\#tk

61. Pang $\mathrm{Y}$, Lee CM, Wright $M$, Shen J, Shen B, Bo J. Challenges of case identification and diagnosis of autism spectrum disorders in China: A critical review of procedures, assessment, and diagnostic criteria. Research in Autism Spectrum Disorders. 2018 Sep 1;53:53-66.

62. Paula CS, Cukier S, Cunha GR, Irarrázaval M, Montiel-Nava C, Garcia R, Rosoli A, Valdez D, Bordini D, Shih A, Garrido G. Challenges, priorities, barriers to care, and stigma in families of people with autism: Similarities and differences among six Latin American countries. Autism. $2020 \mathrm{Jul}$ 27:1362361320940073.

63. Zerbo O, Massolo ML, Qian Y, Croen LA. A study of physician knowledge and experience with autism in adults in a large integrated healthcare system. Journal of Autism and Developmental Disorders. 2015 Dec 1;45(12):4002-14.

64. Sun X, Allison C, Auyeung B, Baron-Cohen S, Brayne C. A review of healthcare service and education provision of Autism Spectrum Condition in mainland China. Research in Developmental Disabilities. 2013 Jan 1;34(1):469-79.

65. https://www.canada.ca/en/public-health/services/diseases/autism-spectrum-disorder-asd/supportautism-spectrum-disorder-asd.html 
66. https://www.newswire.ca/news-releases/government-of-canada-supports-social-enterprise-initiative-incalgary-that-will-benefit-canadians-with-autism-spectrum-disorder-513292481.html

67. Paula CS, Fombonne E, Gadia C, Tuchman R, Rosanoff M. Autism in Brazil: perspectives from science and society. Revista da Associação Médica Brasileira. 2011 Feb;57(1):2-5.

68. https://link.springer.com/content/pdf/10.1007\%2F978-1-4614-6435-8 102024-1.pdf

69. Munoz-Soto R, Becerra C, Noël R, Barcelos T, Villarroel R, Kreisel S, Camblor M. Proyect@ matemáticas: A learning object for supporting the practitioners in autism spectrum disorders. In2016 XI Latin American Conference on Learning Objects and Technology (LACLO) 2016 Oct 3 (pp. 1-6). IEEE.

70. https://www.autism-anglia.org.uk/practical-advice-funds-grants

71. https://ec.europa.eu/research/infocentre/article en.cfm?andartid=49798andcaller=other

72. Taylor L, Eapen V, Maybery MT, Midford S, Paynter J, Quarmby L, Smith T, Williams K, Whitehouse AJ. Diagnostic evaluation for autism spectrum disorder: a survey of health professionals in Australia. BMJ open. 2016 Sep 1;6(9):e012517.

73. https://jsis.washington.edu/seac/news/a-brief-description-of-autism-care-and-management-inindonesia/

74. https://theaseanpost.com/article/what-southeast-asia-doing-about-autism

75. https://yourstory.com/socialstory/2019/04/organisations-india-awareness-autism-educationgbw039jmqw\#: :text=A\%20developmental\%20disorder\%2C\%20autism\%20is,the\%20Rehabilitation\%20C ouncil\%20of\%20India.

76. Vyas AG, Kori VK, Rajagopala S, Patel KS. Etiopathological study on cerebral palsy and its management by Shashtika Shali Pinda Sweda and Samvardhana Ghrita. Ayu. 2013 Jan;34(1):56.

77. https://www.deccanherald.com/content/327167/down-syndrome-still-fatal-india.html 


\section{Appendix A}

\section{Questionnaire for Therapists (therapists + psychologists)}

Q1. In a month, how many new neurodiverse patients approach you for a consultation?

Q2. What age group do you usually work with? Gender division?

Q3. What is the duration of a session? How many sessions do you take in a day?

Q4. What is the general route of diagnosis followed? Are you the $1^{\text {st }}$ Medical POC? If not, then what is the general diagnostic flow?

Q5. What are the initial symptoms that prompt the families/patients to visit you?

Q6. Do the patients (if 18 or older) or the parents/families have prior knowledge/information about the condition/disorder? How informed are they?

Q7. How do you collect data for your clients? Digital or non-digital?

Q8. Have you had any experiences where the individual was at ease with his/her condition, but hid the symptoms \& the therapy visits from his/her parents or family? If yes, what could be the reason?

Q9. Are parents allowed to supervise the sessions? Why/ Why not?

Q10. Have you faced any counter-queries or doubts about the prescribed medicines \& treatment approach? If yes, then how do you tackle it?

Q11. How comfortable are the patients in continuing with regular follow-ups?

Q12. What are the kinds/types of factors you keep in mind when drawing a recommendation plan?

Q13. Where does your role stop in the treatment \& rehabilitation journey of the patient?

Q14. Do you think it is important for professionals to coordinate while working on a patient? Share your thoughts.

Q15. Across the globe, several studies have shown "delay in diagnosis" to be a prevalent cause in creating problems for both parents \& HCPs. Why do you think this happens in India? How would you change it?

Q16. Do you think the knowledge of Neurodiverse conditions among HCPs is low in India?

Q17. What are the drawbacks of the existing system of diagnosis \& treatment for neurodiverse conditions?

\section{Questionnaire for Paediatricians}

Q1. In a month, how many new neurodiverse cases of children do you encounter? What are the most common conditions/disorders you come across?

Q2. What age group do you usually work with? Gender?

Q3. What is the general route of diagnosis followed? Are you the $1^{\text {st }}$ Medical POC? If not, then what is the general diagnostic flow?

Q4. What are the initial symptoms that prompt the families/patients to visit you? 
Q5. What is the general reaction of parents when they find out about such conditions?

Q6. Do the parents/families have prior knowledge/information about the condition/disorder? How informed are they?

Q7. How do you collect data for your clients?

Q8. Have you faced any counter-queries or doubts about the prescribed medicines \& treatment approach? If yes, then how do you tackle it?

Q9. How comfortable are the patients in continuing with regular follow-ups?

Q10. What are the kinds/types of factors you keep in mind when drawing a recommendation plan?

Q11. Where does your role stop in the treatment \& rehabilitation journey of the patient?

Q12. In transitioning into adulthood, changing GP/HCPs, do you think this process could be uncomfortable or be a source of trauma for the neurodivergent child?

Q13. Do you think it is important for professionals to coordinate while working on a patient? How do you coordinate with the other stakeholders in the ecosystem?

Q14. Across the globe, several studies have shown "delay in diagnosis" to be a prevalent cause in creating problems for both parents \& HCPs. Why do you think this happens in India? How would you change it?

Q15. Do you think certain medical professionals or therapists have a lack of knowledge about existing neurodiverse conditions? Uninformed approach?

Q16. What are the drawbacks of the existing system of diagnosis \& treatment for neurodiverse conditions?

\section{Questionnaire for Academics}

Q1. Which school/organization do you work at? Identify your role

Q2. In one semester, how many new cases of neurodiversity approach you for guidance/assistance?

Q3. What age group do you usually work with? Gender division?

Q4. How many hours/sessions do you dedicate per day to children with special needs?

Q5. Where does your role as an academician start? Do medical professionals guide the parents to visit you?

Q6. What are the initial symptoms/reasons that prompt the families/patients to visit you/school?

Q7. What is the kind of facilities \& support systems available in your institute for children with special needs?

Q8. How is the coordination among the different teaching \& academic professionals in the school?

Q9. How do you collect data for your students? Report generation? Digital/Non-digital?

Q10. How do you interact with the other professionals involved in taking care of the child?

Q11. Do you provide any kind of guidance/support to the parents? Describe your interactions with them 
Q12. How frequently do you update yourself with training, literature, materials for educating students with special needs?

Q13. Where does your role stop as an educator?

Q14. What is your opinion on increasing inclusivity in the education sector? How inclusive should regular schools be of children with special needs?

Q15. Challenges/ drawbacks of the Indian education system for neurodiverse individuals 


\section{Questionnaire for Parents}

Warm-up Qs:

Where do you live?

Are you working/homemaker?

How old is your child?

What age did he get diagnosed with the condition?

What is your favourite part of the day with your child?

Q1. What is the medical diagnosis of your child? (syndrome/condition/disorder)

Q2. What was the reason that you made the first visit to a medical professional? (first symptoms)

Q3. Take me through the diagnostic journey, which medical POC did you contact first, what was the route followed?

Q4. How many different service providers evaluated your child before you were given a diagnosis?

Q5. What is the length of time (number of months) between your first concern and receiving a diagnosis for your child? At what age, in years, did your child receive an accurate diagnosis?

\section{Learning about the condition + how to get help}

Q6. Have you heard of this condition before? Did you know anything about it before visiting a medical professional? (prior knowledge)

Q7. Who briefed you about it? What was the support that you received? Did you feel supported (support system)

Q8. Who are the different professionals involved in the care ecosystem for your child today?

Q9. Do/did you receive training from a professional on how to provide therapy at home for your child?

Q10. How do you keep up with the different therapy sessions?

Q11. How do you feel the interaction with different professionals takes place?

Q12. Do you think it would help if there was one common digital platform for all stakeholders?

Q13. Could you describe a usual day for you? How does a normal day with your child look like? (Daily routine)

Q14. What kind of support does you/your child receive from the school? Extra classes, remedial teachers, school counselling sessions, special education? Did you try for a regular school? Education sector well equipped to handle Neurodiverse individuals? Changes?

Q15. Are you a part of any Neurodiverse support groups/clubs? How did you come across it? If there was an ideal group, you could be a part of, what would it be like? Do you interact with the group/silent observer?

Q16. Do you have any kind of health insurance for your child? What kind of insurance? What are the services covered by health insurance?

Q17. What are your future goals for your child? What do you want to see in the areas of education, vocation, living arrangements, etc.? 
Q18. Have you thought of financial planning for your child? (education, therapy, medication, loans)

Q19. What is your opinion about the Indian healthcare system for Neurodiverse individuals? What are its perks \& shortcomings? What would you like to change? 